\title{
REVIEW \\ Fundamental aspects of postharvest heat treatments
}

\author{
Susan Lurie ${ }^{1}$ and Romina Pedreschi ${ }^{2}$;
}

Heat treatments have been investigated for use in many aspects of postharvest storage. They have been developed for insect control, prevention of fungal development and prevention of postharvest storage disorders including chilling injury. The treatment times and temperature range vary widely, from days at $35{ }^{\circ} \mathrm{C}$ to $39{ }^{\circ} \mathrm{C}$ in hot air, to up to $63{ }^{\circ} \mathrm{C}$ for less than a minute in hot water. Much of the research has been performed to develop solutions to a particular problem, and less investigation has been conducted on the responses of the commodity to the treatment. However, since the turn of the century, a number of groups have been active in examining the molecular responses and changes that occur in commodities during and after the heat treatment. This review examines the changes at the level of transcriptome, proteome and metabolome that occur in response to the different heat treatments.

Horticulture Research (2014) 1, 14030; doi:10.1038/hortres.2014.30; published online: 25 June 2014

\section{INTRODUCTION}

Postharvest heat treatments of fruit are used for insect disinfestation, disease control, to modify fruit responses to cold stress and maintain fruit quality during storage. ${ }^{1-5}$ The temperature and exposure duration for a particular crop for a particular purpose are usually determined empirically. Conditioning treatments at temperatures from $30{ }^{\circ} \mathrm{C}$ to $40{ }^{\circ} \mathrm{C}$ in hot air (HAT) for times ranging from hours to days have been developed to affect commodity quality and storability. ${ }^{1}$ Higher temperatures are normally used for either insect or microorganism control. Some treatments which have commercial approval for insect control involve either vapor heat or hot water immersion of the fruit until the core temperature reaches $47{ }^{\circ} \mathrm{C}$, which takes a number of hours unless radiofrequency is involved. ${ }^{5}$ Other treatments, involving hot water dips (HWT), are for a few minutes at temperatures of $50-56{ }^{\circ} \mathrm{C}$ to control fungal pathogens. In addition, there is a short (10-25 s) treatment of hot water rinsing and brushing (HWB) which may involve temperatures of up to $63{ }^{\circ} \mathrm{C} .{ }^{4}$

Much of the published research describes the phenological and physiological responses of a fruit or vegetable to heat treatment. In some studies, biochemical data were gathered on heat shock proteins (HSPs), and other stress proteins such as pathogen resistant (PR), antioxidants, etc. However, the greatest number of studies have been concerned with developing an effective treatment against a problem, be it insect pest, pathogen attack or storage disorder.

This review will focus on the molecular responses of fruit and vegetables to postharvest high temperature stress. It will summarize what has been published in the twenty-first century, and emphasize the 'omics' studies; metabolomics, proteomics and transcriptomics. It will not deal with research on the effect of high temperature on minimally processed produce, which is of interest in itself. Nor will it deal with heat damage, which is also of importance. ${ }^{6}$ The body of knowledge that is being gathered in these studies will help in developing more accurate treatments with less possibility of unwanted side effects to the commodity.

\section{HEAT STRESS RESPONSE}

Temperature is one of the most important environmental factors that regulate plant growth and development. Plants have evolved signaling pathways to sense changes in ambient temperature and adjust their metabolism and cell function to prevent heat-related damage. Many features of the heat stress response pathway are conserved among both prokaryotic and eukaryotic organisms. ${ }^{7}$ Because plants are sessile organisms that cannot escape stress conditions, they invest valuable resources in modifying their metabolism to prevent damage caused by heat, in a process referred to as acclimation, or acquired thermotolerance. ${ }^{7,8}$ The accumulation of HSPs, under the control of heat stress transcription factors (HSFs), plays a central role in the heat stress response and in acquired thermotolerance in plants and other organisms.

Heat stress affects the stability of various proteins, membranes, RNA species and cytoskeleton structures, and alters the efficiency of enzymatic reactions in the cell, causing metabolic imbalance. ${ }^{9-11}$ Disrupting the steady-state flux of metabolites can cause the accumulation of toxic compounds, such as reactive oxygen species (ROS). In fact, ROS is generally a component of heat stress and increases in antioxidant processes are part of the heat stress response. ${ }^{8,12}$ As a response to heat stress, plants reprogram their transcriptone, proteome, metabolome and lipidome (Figure 1). These changes establish a new steady-state balance of metabolic processes that can enable the organism to function at the new temperature. This new balance may also be helpful in responding to other stresses, such as the low temperatures of storage.

A high temperature will affect most macromolecules and will cause changes such as increased membrane fluidity, partial melting of DNA and RNA strands, protein subunit disassociation and exposure of hydrophobic cores. The specific change which might be a sensor of high temperature stress is unknown, and may be different in different plants. The classical model for heat stress activation involves HSFs. Heat-stressed unfolded proteins in the cell cause molecular chaperones to be released from their constitutive inhibitory association with HSF monomers and to bind the unfolded proteins, while the free HSF subunits trimerize, undergo phosphorylation and bind to heat shock response promoters in the genome to activate heat stress responses. ${ }^{13}$ However, mild heat stresses may not lead to protein unfolding and yet the plant shows a stress response. Other models which appear to be dominant in some situations include; a specific calcium channel opening in the plasma membrane due to heat-induced changes in membrane fluidity, ${ }^{14}$

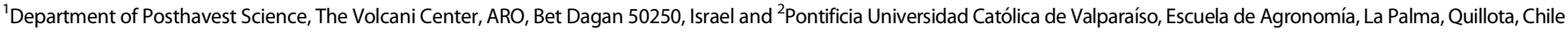
Correspondence: S Lurie (slurie43@agri.gov.il)

Received: 6 March 2014; Revised: 8 April 2014; Accepted: 1 May 2014 


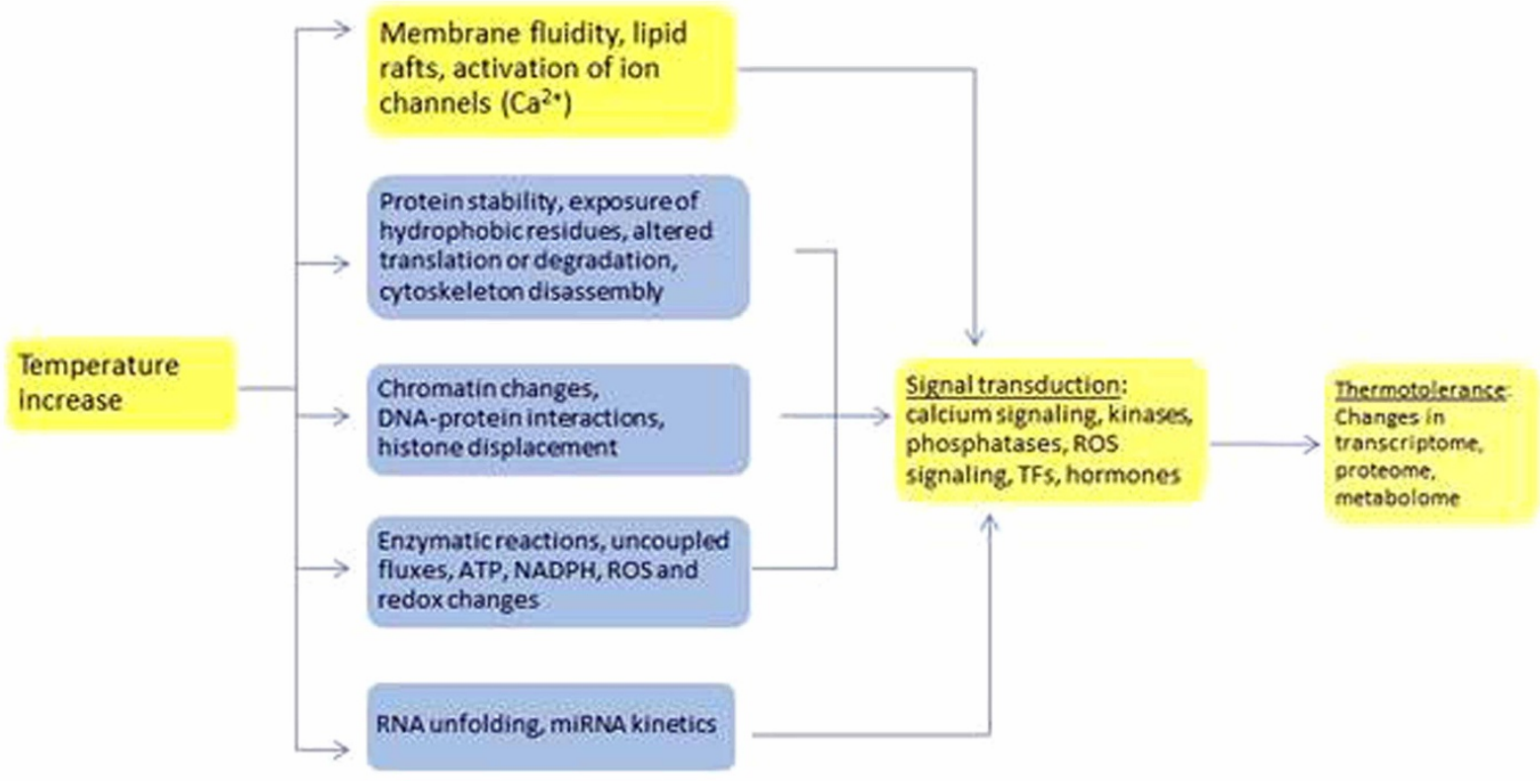

Figure 1. A schematic model for temperature sensing in plants. Changes in temperature can alter membrane properties and activate a calcium channel. The inward flux of calcium that follows will activate signal transduction events and alter plant metabolism to achieve thermotolerance. Additional temperature-induced changes include alterations in protein stability and exposure of hydrophobic residues of proteins that may trigger ubiquitin in the cytosol and the ER, histone displacement which allows HSFs to bind to DNA, accumulation of ROS and alteration in cellular energy levels, and unfolding of RNA species that could affect miRNA. These pathways will also trigger different signal transduction events and lead to thermotolerance (adapted from Mittler et al., ${ }^{8} 2012$ ).

lipid signaling due to membrane fluidity changes ${ }^{15,16}$ and ROS signaling, particularly the respiratory burst mediated by a plasma membrane NADP oxidase. ${ }^{12}$ It is noteworthy that these models all include some action at the plasma membrane, which is also the suggested site of response to cold stress. Recently, there has been some evidence that smRNAs may also be involved in responses to heat stress, although so far only as response to high temperature and not involved in acquired thermotolerance. ${ }^{17,18}$

Attempts to increase thermotolerance by overexpression of a single gene have limited impact because of the genetic complexity of the heat stress response. ${ }^{19}$ Data from genome wide expression profiles of Arabidopsis plants exposed to heat stress, from different plant species experiencing heat stress, from different tissue types, developmental stages and different duration of the stress, give some commonality of patterns of transcript accumulation, with between $2 \%$ and $5 \%$ of the genome being affected. ${ }^{20,21}$ Therefore, it would be unlikely that one gene could cause more than a qualitative change in the response of an organism to heat stress.

\section{HEAT TREATMENT OF POSTHARVEST COMMODITIES}

Harvested commodities are invariably exposed to low temperature in order to retard product respiration and delay ripening and senescence. Many commodities will develop chilling injury if the temperature is too low or if the cold conditions are maintained for too long. Heat treatments have been found many cases to delay or prevent the development of chilling injury. ${ }^{1}$ This has been shown in many commodities to be associated with the prolonged presence of HSPs in the tissue and the protective effect they exert. ${ }^{2,2-25}$ HSPs increase during a heat stress and generally disappear rapidly when a plant is returned to ambient temperature. Sabahat et al. ${ }^{26}$ were the first to show that if a commodity was placed at $2{ }^{\circ} \mathrm{C}$ rather than $20{ }^{\circ} \mathrm{C}$ following a heat stress the HSPs were not metabolized. Thus, the thermotolerance induced in a heat stress can give protection against cold stress.
Postharvest heat treatments also alter the normal program of protein synthesis and cellular metabolism during heat stress. When heat stress is imposed, there is a rapid disassociation of polyribosomes and protein synthesis stops briefly and then resumes with a new set of proteins including the HSPs. ${ }^{27}$ The consequence of this switch is that normal ripening processes are inhibited, and, if the commodity is then placed in low temperature, the inhibition persists for some time. When rewarmed after storage ripening resumes. Therefore, postharvest heat treatments can modulate the rate of ripening of commodities, while, in addition, preventing postharvest storage disorders.

Studies of changes in transcriptome, proteome and metabolome of a number of fruits due to a postharvest heat treatment have been published. The commodities examined include citrus, mango, peach, potato and tomato (Table 1).

\section{CITRUS}

Citrus fruits are susceptible to chilling injury when exposed to temperatures lower than $2-5{ }^{\circ} \mathrm{C}$. High temperature treatments using $\mathrm{HAT}^{28}$ and $\mathrm{HWT}^{29,30}$ can delay the appearance of chilling injury and inhibit fungal infection. Sala and Lafuente ${ }^{28}$ found a correlation between catalase (CAT) activity and resistance to chilling injury when mandarins were stored at $2{ }^{\circ} \mathrm{C}$ following a 3 min HWT at $53{ }^{\circ} \mathrm{C}$ or 3-day HAT at $38{ }^{\circ} \mathrm{C}$ hot air. They did not find induction of ascorbate peroxidase (APX), glutathione reductase or superoxide dismutase (SOD) in the heated fruit. This treatment of HAT can also increase polyamine concentration and the increase correlated with lower chilling sensitivity of mandarins. ${ }^{31}$

The most common treatment for citrus is a HWT for 2-3 min at temperatures of $50-53{ }^{\circ} \mathrm{C}$ to control fungal development. Yun et al. $^{32}$ conducted a proteomic and metabolomic study of mandarin peel during storage after a $2 \mathrm{~min} \operatorname{dip}$ at $52^{\circ} \mathrm{C}$. This treatment successfully suppressed Penicillium italicum development, and reduced chilling injury during storage. Two-dimensional gel electrophoresis (2-DE) found 50 proteins (out of 600 detected spots) that were 


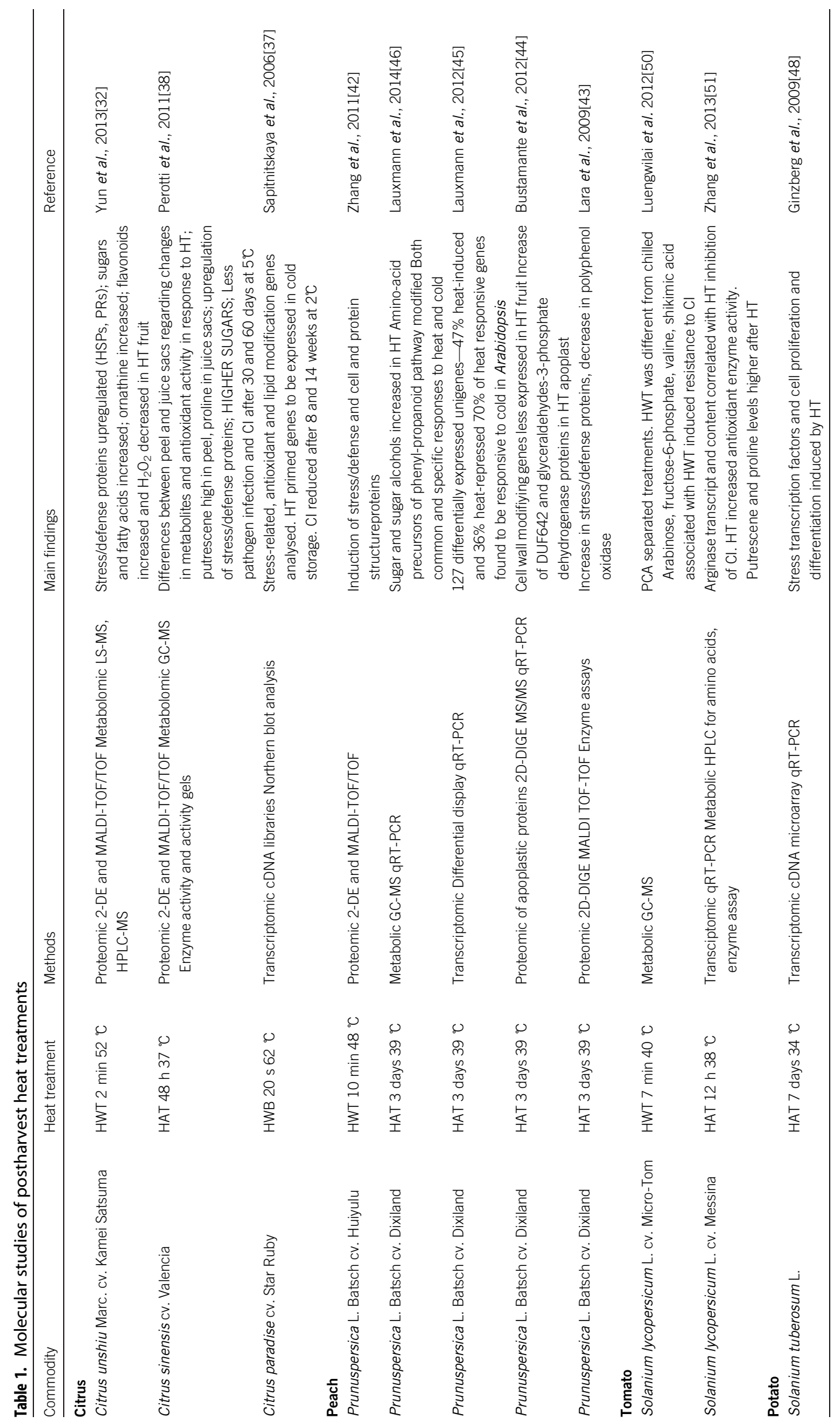


altered at least 1.5 -fold between heated and control fruit during storage ranging from 1 to 39 days after treatment. These proteins fell into the categories of glycolysis and TCA cycle, redox regulation, stress response and protein folding. The stress proteins were higher in the heated fruit and included HSPs and PR proteins, and some remained higher than control for up to 39 days after treatment. The ROS metabolism-related proteins that were found differentially in the 2-DE gels were lower during storage in heat treated fruit, and included a number of oxidoreductases and Cu/Zn SOD. However, a chloroplast APX was induced by the heat treatment and remained high in storage. CAT was not found differentially in this study. Although the ROS enzymes were not higher in the heated fruit, $\mathrm{H}_{2} \mathrm{O}_{2}$ decreased in the heat treated fruit during storage, while it increased in the control fruit.

The metabolomic study identified 62 metabolites which were grouped into alcohols, amino acids, sugars, organic acids and fatty acids. ${ }^{32}$ Most sugars and fatty acids increased in the peel after HWT, but the sugar levels returned to control levels during storage. Organic acids were lower immediately after HWT and then recovered to a higher level than control fruit during storage. Amino acids were also decreased by HWT, but remained lower than control even during storage. An exception was ornithine which was 2.5 times higher than control fruit. This amino acid is required for the synthesis of polyamines and alkaloids, which contribute to abiotic stress tolerance in plants. ${ }^{33}$

Immediately after the HWT, many flavonoids were much higher than in control fruit, including quercitin, hesperetin, naringenin and rutin. Most of these have antioxidant activity and may have contributed to the decrease in $\mathrm{H}_{2} \mathrm{O}_{2 \cdot-}{ }^{34,35}$ Some also have antimicrobial properties. ${ }^{36}$ Most increases in these compounds disappeared during the first few days of storage.

A transcriptomics approach ${ }^{37}$ found many similarities to the proteomic results of Yun et al. ${ }^{32}$ The treatment was a HWB of grapefruit for $20 \mathrm{~s}$ at $62{ }^{\circ} \mathrm{C}$, and the fruit were stored at $2{ }^{\circ} \mathrm{C}$ for 8 and 14 weeks. There was $80 \%$ decrease in chilling injury in the fruit after storage. cDNA libraries were constructed and sequenced and then subtraction analysis was performed. Eleven different cDNAs were evaluated after the HWB and cold storage. These were six stressresponsive, three antioxidant and two lipid modification genes chosen for verification with RNA Northern blots. The HSPs were highly expressed following the HWB as were other stress genes such as dehydrin and glucanase. Lipid modifying genes, fatty acid desaturase, lipid transfer protein and lipase were induced by HWB and decreased in storage. The antioxidant genes of SOD and CAT increased during cold storage. Many of the gene expression patterns showed a priming effect from the HWB; the expression was not higher immediately after the treatment, but increased over time during exposure to chilling.

In contrast to the HWT and HWB which are short heat treatments, antioxidants were increased by in oranges by a HAT for $48 \mathrm{~h}$ at $37^{\circ} \mathrm{C}$ followed by storage at $5{ }^{\circ} \mathrm{C}$ for 30 and 60 days. ${ }^{38}$ Proteomics was conducted on both flavedo (peel) and juice sacs, and activity gels were also run for SOD, POD and APX. The activity of all three enzymes increased after HAT and remained higher than control fruit during storage. CAT and glutathione reductase activities did not change due to HAT. From the proteomic 2-DE results of juice sacs, 61 differential protein spots (out of 500 spots) were detected, either after the HAT or after 30 or 60 days of storage. The classes of proteins increased by the HAT were defense, including both HSPs and $P R$ proteins, and metabolism. However, after 60 days at $5^{\circ} \mathrm{C}$, the differential spots found between HAT or control fruit were all higher in the control fruit. Metabolic analysis was made of both flavedo and juice sacs after treatment and after 60 days of storage and 28 compounds were analyzed. Sugars were higher in the HAT at both time points. The main organic acids in the juice, citric and malic, were not affected by the HAT, while they decreased in the flavedo initially and then recovered during storage as occurred in the HWT of Yun et al. ${ }^{32}$ Glycerol and putrescine increased in the HAT flavedo, while proline was very high in the fruit sacs. Proline has been found to be correlated in many plants with adaptation to cold temperatures. ${ }^{39}$ Putrescine, one of whose precursors ornithine was high in HWT mandarins, ${ }^{32}$ was also found by Gonzalez Aguilar et al. ${ }^{31}$ to increase in mandarins during HAT. Putrescine is essential to counteract cold stress in Arabidopsis ${ }^{40}$ and to allow ABA increases in cold stressed plants. ${ }^{41}$

\section{PEACH}

Peach fruit has been subjected to both HWT and HAT to study molecular changes in the fruit. A HWT of $48{ }^{\circ} \mathrm{C}$ for 10 min followed by shelf life was used to examine proteome changes during ripening. ${ }^{42}$ Using 2-DE, 600 protein spots were detected and 35 differentially expressed spots were analyzed. Almost half of the proteins identified were stress and defense, including antioxidants. As in the study of HWB of grapefruits, ${ }^{37}$ in many cases, the increase in protein level occurred with a delay of a day or two after the treatment. Both APX and DHAR were higher in protein abundance 1 and 3 days after the treatment, as were two HSPs.

A series of papers have been published detailing changes in peach fruit due to a HAT of $39^{\circ} \mathrm{C}$ for 3 days. ${ }^{43-46}$ This treatment was found to delay internal breakdown development in stored peaches, although it enhanced the red coloration in both peel and flesh. ${ }^{47}$ A study by Lara et al. ${ }^{43}$ followed the recovery of the fruit from the heat stress, and the resumption of ripening which was inhibited during HAT, particularly softening and ethylene gene expression.

$D$-glucose, $D$-fructose, sucrose, sorbitol, malic acid and citric acid were determined using enzymatic kits. The analysis of these metabolites showed that, as in citrus, sugars (glucose, fructose, sorbitol) were higher than in control fruit during and following the HAT, while organic acids (citric and malic) were lower. Sucrose degradation, and glycolic- and fermentation-related enzyme activity and transcript levels by qRT-PCR were analyzed after HAT and 3 days later. Enzyme activity and expression levels of invertases (both acid and neutral), pyruvate kinase and pyruvate decarboxylase, ATPdependent and PPi-dependent phosphofructokinase were higher in HAT fruit 3 days after the treatment than in control fruit, though not at the end of the heat treatment. A 2D-DE examination of peach proteins detected 600 spots, and 57 were significantly affected by temperature. Forty-four differential proteins were identified. Twenty-seven percent of the identified proteins corresponded to HSPs. Some of these appeared during the HAT, while others increased following the treatment. An examination of the extracellular proteins of the fruit at harvest found the most abundant proteins were proteases, peroxidases, a porin and a small HSP. ${ }^{44}$ In HAT fruit, a glyceraldehydes-3-phosphate dehydrogenase was abundant, and was localized to the cell wall by immunolocalization. qRTPCR expression analysis of cell wall modifying genes (which were not identified in the proteome study, perhaps because the technique extracted only weakly bound cell wall proteins) had lower expression during HAT, corresponding to inhibited softening.

A transcriptomic and metabolomic study was conducted on the HAT peaches, after they were placed at $0{ }^{\circ} \mathrm{C}$ for a 5 days, with the purpose of determining which responses and metabolic pathways were activated in both stresses and which were confined to either heat or cold. ${ }^{45,46}$ Differential transcriptome analysis of the peaches found 127 unigenes that were differentially expressed among heated or unheated placed at $20{ }^{\circ} \mathrm{C}, 60$ unigenes were induced by the HAT and 45 unigenes were repressed. ${ }^{45}$ Twenty percent of the genes were involved in protein modification, transcription and RNA metabolism. This group may be responsible for the signal transduction leading to the previously reported proteomic changes. ${ }^{42,43}$ Another functional group of genes over-represented in induced genes were those responsive to heat, cold or freezing 
stress. A group of genes that were either induced or repressed by HAT were chosen for further examination and their expression determined in peaches placed at $0{ }^{\circ} \mathrm{C}$. It was found that $75 \%$ of the HAT induced and $95 \%$ of the HAT genes repressed were activated similarly by a cold treatment. When the unigenes from peach were compared to Arabidopsis orthologs, $70 \%$ of them were responsive to cold. The conclusion of this study was that the heat treatment activates many of the same genes that cold stress does, and that some of them confer to the fruit resistance to chilling injury.

The metabolomic study identified 47 metabolites. ${ }^{46}$ A PCA analysis of these compounds explained $65 \%$ of the variance by three principal components. PC1 separated HAT fruit (both at time of treatment and after removal to $20{ }^{\circ} \mathrm{C}$ or $2{ }^{\circ} \mathrm{C}$ ) from all other samples. PC2 separated harvest from all other samples, while PC3 grouped the samples according to temperature regime, with $20{ }^{\circ} \mathrm{C}$, HAT and $0{ }^{\circ} \mathrm{C}$ all clustering separately. This is quite different from the transcriptome study where there was a convergence of transcripts activated by both heat and cold stress.

The metabolites fell into the same classes as were analyzed in the citrus studies; sugars, organic acids, amino acids, fatty acids, and also putrescine and urea. ${ }^{32,38}$ The peach study did not include analysis of flavonoids as was done in citrus. Changes in the metabolome of peach during and after HAT showed similarity to changes in citrus. The sugars and alcohol sugars were increased in HAT and most remained high when fruit were transferred to $20{ }^{\circ} \mathrm{C}$, though fructose and glucose returned to control fruit levels. Galactinol was the most elevated by HAT and remained high if fruit were placed in $0{ }^{\circ} \mathrm{C}$, but not when they were put at $20{ }^{\circ} \mathrm{C}$. Organic acids tended to decrease in HAT fruit compared to their levels at harvest, similar to their behavior in citrus peel. ${ }^{32,38}$ However, when the same time point was compared (the 3 days HAT compared to 3 days $20^{\circ} \mathrm{C}$ ) citrate was twice as high, while 2-oxoglutarate, malate and glycerate were $50 \%$ lower in content. The amino acid levels in citrus were decreased by HWT, while in HAT peach fruit, 10 out of 14 amino acids were modified, with most increasing either during or after the HAT. Two fatty acids, tetradecanoic and octadecanoic showed opposite responses to HAT with the former increasing and the latter decreasing, similarly to their changes in citrus peel. ${ }^{32}$ Putrescine, which increased in citrus after HAT, ${ }^{38}$ was lower in HAT peach fruit.

\section{POTATO}

The transcriptomic study of potato tubers was for a different purpose than the studies on heat treatment of other commodities. Under adverse growing conditions, particularly high temperature, the skin separates from the other layers and russeting occurs, so the study was to determine gene expression that might be involved in this disorder, as opposed to other commodities where a high-temperature treatment was to develop resistance to storage disorders. The outer periderm tissue of the tuber is made up of three tissue types; phellem, phellogen and phelloderm. As phellem cells become suberized and die, they form a protective layer termed 'skin'. The phelloderm cells are the innermost layer of the periderm and contain actively dividing cells during tuber maturation. A transcriptomic study was made of periderm tissue of potato tubers utilizing a cDNA microarray containing 11412 cDNA clones to identify genes involved in the periderm response to heat stress. ${ }^{48}$ Skin and phelloderm were collected separately from tubers exposed to soil temperatures of $33{ }^{\circ} \mathrm{C}$ for a week. In skin tissue, 86 genes were increased and 189 repressed by the heat, while in periderm, 167 genes were increased and 91 were repressed. The major functional group that was differentially expressed in both skin and phelloderm was stress and defense related genes. The major upregulated phelloderm genes were HSPs, while in the skin, they were genes involved in the development of protective/ symbiotic plant-microbe interactions (including PR proteins). The transcription factors which were differentially expressed in HAT tissue were those for stress response (33\%) and cell proliferation and differentiation (28\%). The data suggest that during high temperature, increased periderm/skin layers are produced, leading to reduced flexibility and cracking as the tuber continues to grow. The periderm is a protective tissue containing a wide array of plant defense components. ${ }^{49}$ The enhanced cell proliferation activity could be part of the response to heat stress, by creating an insulating cover and preventing water loss from the tuber flesh.

\section{TOMATO}

Two studies have recently been published on the ability of heat treatment to prevent chilling injury in tomato. ${ }^{50,51}$ Early work on tomato showed that high temperature conditioning of tomato fruit before storage at chilling temperatures $\left(<10{ }^{\circ} \mathrm{C}\right)$ mitigated the development of chilling injury. ${ }^{52}$ This mitigation is correlated with altered protein synthesis including accumulation of HSPs and inhibition of normal ripening processes. ${ }^{26,53}$ However, other processes may be involved in the preconditioning mitigation of chilling injury. Low-temperature stress causes changes in the accumulation of distinct metabolites in many plant tissue, and changes in the levels of a subset of metabolites in response to preconditioning may contribute to induced chilling tolerance. ${ }^{54}$ Metabolic profiling was made of Micro-tom tomatoes comparing control fruit to HWT fruit at $40{ }^{\circ} \mathrm{C}$ for $7 \mathrm{~min}$ and then held at $20{ }^{\circ} \mathrm{C}$ or $2.5{ }^{\circ} \mathrm{C}$ for 14 days. ${ }^{50}$ Sixty-five metabolites were identified from polar extracts of the fruit. PCA analysis explained $75 \%$ of the variance, but the best separation among the treatments was on the PC2 axis which just explained $6 \%$ of the variance. This indicates that the metabolites in the samples were quite similar. Examining the metabolites which contributed to PC2 found that low temperature increased arabinose, citric acid, dehydroascorbic acid, fructose-6-phosphate, glucose-6-phosphate, rhamnose and valine, and decreased glutamic acid and shikimic acid. HWT caused increases in four sugars, three organic acids, one fatty acid, one amino acid, as well as allantoin and putrescine, and the levels remained high during cold storage. The authors suggest that the increases in arabinose and fructose-6phosphate which occur in chilled fruit, but not in HWT and chilled fruit may be markers for chilling injury.

Zhang et al. ${ }^{51}$ investigated the role of the products of the arginine pathway in contributing to resistance to chilling injury. Arginine is a precursor of polyamines, proline and nitric oxide as well as proteins. Arginase catalyzes the hydrolysis of arginine to urea and ornithine, which is the precursor of putrescine and proline. All these compounds have been found to be present at elevated levels in various heated fruit, including citrus and peach. ${ }^{32,38,46}$ Tomato fruit HAT treated at $38{ }^{\circ} \mathrm{C}$ for $12 \mathrm{~h}$ and stored at $2{ }^{\circ} \mathrm{C}$ did not develop chilling injury. Transcript level and activity of arginase were induced by HAT. Following HAT, the stored fruit had higher levels of arginine, proline and putrescine, as well as increased activities of the antioxidative enzymes SOD, CAT and APX. Pre-treatment with an arginase inhibitor cancelled these changes evoked by the HAT.

\section{CONCLUSIONS}

There are a number of common themes that run through most of the studies reported here. One is that changes induced by high temperature persist for an extended time, sometimes days and sometimes weeks, when the commodity is placed in low temperature following the heat stress. In the case of short times of exposure to high temperature, the molecular changes may actually occur after the heat stress has ended. The changes involve accumulation of stress and defense proteins, including HSPs, PRs, dehydrins, and antioxidant enzymes and compounds (polyphenols). There is also elevation of sugars and accumulation of putrescince (or its precursors) and proline, both of which have been shown to be involved in adaptation to low temperatures. The study of Lauxmann 
et $a l^{45}$ showed the commonality between the response to heat stress and that of cold.

The times and temperatures given in the studies are very different, ranging from $33{ }^{\circ} \mathrm{C}$ for days to $63{ }^{\circ} \mathrm{C}$ for seconds. In all cases, however, similar changes at the molecular level were obtained. Some of the treatments were long enough so that the changes in gene expression, protein accumulation, and metabolic shifts occurred during the treatment, and in other cases, the treatment primed the tissue to produce the changes after the heat stress.

What is clear from the studies is that more information is acquired from the transcriptomics data than either proteomics or metabolomics. This is undoubtedly due in the case of proteomics to both the sensitivity of the analysis and the cost of analyzing the proteins on the gel. In none of the studies have the majority of protein spots on a gel been analyzed, unlike the full annotation given in transcriptomics studies. In the metabolomic studies, often the extraction is of only one type, for example, polar solvent, ${ }^{50}$ and so other compounds are not analyzed. A thorough metabolomics study is more complicated and would need a number of extractions and assays. ${ }^{32}$ In the future, these techniques will undoubtedly become more standardized and less expensive and will lead to a more thorough understanding of the changes occurring during high temperature treatment.

One area which was not examined thoroughly in any of the studies reported here was an analysis of the transcription factors and signaling pathways or networks that are involved in the tissue response to a heat treatment. Possibly this is because the studies involved the responses at the end of the stress and during subsequent storage, while the signaling would have been maximal at an early stage of the treatment. However, I am certain that the HSFs are not the only transcription factors involved in complicated response of the tissue to heat stress, and elucidation of these pathways will help untangle the responses.

Currently the research in this field is at the stage of accumulating knowledge without regard to practical application. Since there are many responses to heat treatment that are the same in the different fruit that have been studied so far, it may be possible to choose a model fruit, such as tomato, to conduct a meta-analysis. Ideally, such a study would include different heat treatments, different stages of fruit ripeness and an analysis of all the changes from gene activation through protein and metabolite production. One potential practical outcome could be the development of markers, either a metabolite, stress compound or transcription level of a gene, which would indicate the efficacy of a treatment. As mentioned in the introduction, treatments are developed empirically by trial and error. A more precise measurement of how the plant tissue is responding to the high temperature could help in developing better treatments.

\section{CONFLICT OF INTEREST}

The authors declare no conflict of interest.

\section{REFERENCES}

1 Lurie S. Postharvest heat treatments. Postharvest Biol Technol 1998; 14: 257-269.

2 Lurie S. Postharvest heat treatments of horticultural crops. Hort Rev 1998; 22: $91-$ 122.

3 Paull RE, Chen NJ. Heat treatment and fruit ripening. Postharvest Biol Technol 2000; 21: 21-37.

4 Fallik E. Prestorage hot water treatments (immersion, rinsing and brushing). Postharvest Biol Technol 2004; 32: 125-134.

5 Tang J, Mitcham E, Wang S, Lurie S. Heat Treatments for Postharvest Pest Control: Theory and Practice. Oxon: CABI International, 2007.

6 Ghasemnezhad M, Marsh K, Shilton R, Babbalar M, Woolf A. Effect of hot water treatments on chilling injury and heat damage in 'satsuma' mandarins: antioxidant enzymes and vacuolar ATPase and pyrophosphatase. Postharvest Biol Technol 2008; 48: 364-371.
7 Kotak S, Larkindale J, Lee U, von Koskull-Doring P, Vierling E, Scharf KD. Complexity of the heat stress response in plants. Curr Opin Plant Biol 2007; 10: 310-316.

8 Mittler R, Finka A, Goloubinoff P. How do plants feel the heat? Trends Biochem Sci 2012; 37: 118-125.

9 McClung CR, Davis SJ. Ambient thermometers in plants: from physiological outputs towards mechanisms of thermal sensing. Curr Biol 2010; 20: 1086-1092.

10 Ruelland E, Zachowski A. How plants sense temperature. Environ Exp Bot 2010; 69: 225-232.

11 Suzuki N, Koussevitzki S, Mittler R. ROS and redox signaling in the response of plants to abiotic stress. Plant Cell Environ 2011; 35: 259-270.

12 Konigshofer $\mathrm{H}$, Thromballa HW, Loppert HG. Early events in signaling hightemperature stress in tobacco BY2 cells involve alterations in membrane fluidity and enhanced hydrogen peroxide production. Plant Cell Environ 2008; 31: 17711780.

13 von Koskull-Doring $\mathrm{P}$, Scharf KD, Nover L. The diversity of plant heat stress transcription factors. Trends Plant Sci 2007; 12: 452-457.

14 Saidi $Y$, Finka A, Muriset $M$ et al. The heat shock response in moss plants is regulated by specific calcium permeable channels in the plasma membrane. Plant Cell 2009; 21: 2829-2843.

15 Mishkind M, Vermeer J, Darwish E, Munnik T. Heat stress activates phospholipase D and triggers PIP2 accumulation at the plasma membrane and nucleus. Plant $J$ 2009; 60: $10-21$.

16 Zheng SZ, Liu YL, Li B, Shang ZL, Zhou RG, Sun DY. Phosphoinositide-specific phospholipase C9 is involved in the thermotolerance in Arabidopsis. Plant $J$ 2011; 69: 689-700.

17 Wang $\mathrm{L}$, Yu X, Wang $\mathrm{H}$ et al. A novel class of heat-responsive small RNAs derived from the chloroplast genome of Chinese cabbage (Brassica rapa). BMC Genomics 2011; 12: 289.

$18 \mathrm{Yu} \mathrm{X}$, Wang $\mathrm{H}$, Lu Y et al. Identification of conserved and novel microRNAs that are responsive to heat stress in Brassica rapa. J Exp Bot 2012; 63: 1025-1038.

19 Neta-Sharir I, Isaacson T, Lurie S, Weiss D. Dual role for tomato heat shock protein 21: protecting photosystem II from oxidative stress and promoting color changes during fruit maturation. Plant Cell 2005; 17: 1829-1838.

20 Larkindale J, Vierling E. Core genome responses involved in acclimation to high temperature. Plant Physiol 2008; 145: 748-761.

21 Qin D, Wu H, Peng $\mathrm{H}$ et al. Heat stress-responsive transcriptome analysis in heat susceptible and tolerant wheat (Triticum aestivum L.) by using Wheat Genome Array. BMC Genomics 2008; 9: 432.

22 Zhang $\mathrm{JH}$, Huang WD, Pan QH, Liu Y. Improvement of chilling tolerance and accumulation heat shock proteins in grape berries (Vitis vinifera cv. Jingxiu) by heat pretreatment. Postharvest Biol Technol 2005; 38: 80-90.

23 Yi SY, Sun AQ, Sun Y, Yang JY, Zhao CM, Liu J. Differential regulation of Lehsp23.8 in tomato plants: analysis of a multiple stress inducible promoter. Plant Sci 2006; 171: 398-407.

24 Sevillano L, Mar Sola M, Vargas AM. Induction of small heat-shock proteins in mesocarp of cherimoya fruit (Annona cherimola Mill.) produces chilling tolerance. J Food Biochem 2010; 34: 625-638.

$25 \mathrm{He} \mathrm{LH}$, Chen JY, Kuang, JF et al. Expression of three sHSP genes involved in heat pretreatment-inducing chilling tolerance in banana fruit. J Sci Food Agric 2012; 92: 1924-1930.

26 Sabehat A, Weiss D, Lurie S. The correlation between heat-shock protein accumulation and persistence and chilling tolerance in tomato fruit. Plant Physiol 1996; 110: 531-537.

27 Ferguson IB, Lurie S, Bowen JH. Protein synthesis and breakdown during heat shock of cultured pear (Pyrus communis) cells. Plant Physiol 1994; 104: 1429-1437.

28 Sala JM, Lafuente MT. Catalase enzyme is related to tolerance of mandarin fruit to chilling. Postharvest Biol Technol 2000; 20: 81-89.

29 Schirra M, Agabbio M, D'Hallewin G, Pala M, Ruggiu R. Response of Tarocco orange of picking date, postharvest hot water dips, and chilling storage temperature. J Agric Food Chem 1997; 45: 3216-3220.

30 Schirra M, D'Hallewin G. Storage performance of Fortune mandarins following hot water dips. Postharvest Biol Technol 1997; 10: 229-237.

31 Gonzalez-Aguilar GA, Zacarias L, Perez-Amador MA, Carbonell J, Lafuente MT. Polyamine content and chilling susceptibility are affected by seasonal changes in temperature and by conditioning temperature in cold-stored 'Fortune' mandarin fruit. Physiol Plant 2000; 108: 140-146.

32 Yun Z, Gao H, Liu P et al. Comparative proteomic and metabolomic profiling of citrus fruit with enhancement of disease resistance by postharvest heat treatment. BMC Plant Biol 2013; 13: 44.

33 Kalamaki MS, Alexandrou D, Lazari D et al. Over-expression of a tomato $\mathrm{N}$-acetyl-Lglutamate synthase gene (SINAGS1) in Arabi dopsis thaliana results in high ornithine levels and increased tolerance in salt and drought stresses. $J$ Exp Bot 2009; 60: 1859-1871. 
34 Nijveldt RJ, van Nood E, van Hoorn DE, Boelens PG, van Norren K, van Leeuwen PAM. Flavonoids: a review of probably mechanisms of action and potential applications. Am J Clin Nutr 2001; 74: 418-425.

35 Saviranta NM, Veeroos L, Granlund JL, Hassinen VH, Kaarniranta K, Karjalainen RI. Plant flanonol quercetin and isoflavone biochanin A differentially induce protection agains oxidative stress and inflammation in ARPE-9 cells. Food Res Int 2011; 44: 109-113.

36 Treutter D. Significance of flavonoids in plant resistance: a review. Environ Chem Lett 2006; 4: 147-157.

37 Sapitnitskaya M, Maul P, McCollum GT et al. Postharvest heat and conditioning treatment activate different molecular responses and reduce chilling injuries in grapefruit. J Exp Bot 2006; 57: 2943-2953.

38 Perotti VE, del Vecchio HA, Sansevich A et al. Proteomic, metabolomic, and biochemical analysis of heat treated Valencia oranges during storage. Postharvest Biol Technol 2011; 62: 97-114.

39 Chen WP, Li PH. Membrane stabilization by abscisic acid under cold aids proline in alleviating chilling injury in maize (Zea mays L.) cultured cells. Plant Cell Environ 2002; 25: 955-962.

40 Cuevas JC, Lopez-Cobollo R, Alcazar R et al. Putrescine is involved in Arabidopsis freezing tolerance and cold acclimation by regulating abscisic acid levels in response to low temperature. Plant Physiol 2008; 148: 1094-1105.

41 Cuevas JC, Lopez-Cobollo R, Alcazar R et al. Putrescine as a signal to modulate the indispensable ABA increase under cold stress. Plant Sign Behav 2009; 4: 219-220.

42 Zhang L, Yu Z, Jiang L, Jiang J, Luo H, Fu L. Effect of postharvest heat treatment on proteome change of peach fruit during ripening. J Proteomics 2011; 74: 1135-1149.

43 Lara, MV, Borsani J, Budde CO et al. Biochemical and proteomic analysis of 'Dixiland' peach fruit (Prunus persica) upon heat treatment. J Exp Bot 2009; 60: 4315-4333.

44 Bustamante CA, Budde CO, Borsani J et al. Heat treatment of peach fruit: modifications in the extracellular compartment and identification of novel extracellular proteins. Plant Physiol Biochem 2012; 60: 35-45.

45 Lauxmann MA, Brun B, Borsani J et al. Transcriptomic profiling during the postharvest of heat-treated Dixiland Prunus persica fruits: common and distinct response to heat and cold. PLOS ONE 2012; 7: e51052.
46 Lauxmann MA, Borsani J, Osorio S et al. Deciphering the metabolic pathways influencing heat and cold responses during post-harvest physiology of peach fruit. Plant Cell Environ 2014; 37: 601-616.

47 Murray R, Lucarngeli C, Polenta G, Budde C. Combined pr-storage heat treatment and controlled atmosphere reduced internal breakdown of 'Flavortop' peach. Postharvest Biol Technol 2007; 44: 116-121.

48 Ginzberg I, Barel G, Ophir R et al. Transcriptomic profiling of heat-stress response in potato periderm. J Exp Bot 2009; 60: 4411-4421.

49 Barel G, Ginzberg I. Potato skin proteome is enriched with plant defense components. J Exp Bot 2008; 59: 3347-3357.

50 Luengwilai K, Saltveit M, Beckles DM. Metabolite content of harvested Micro-Tom tomato (Solanium lycopersicum L.) fruit is altered by chilling and protective heatshock treatments as shown by GC-MS metabolic profiling. Postharvest Biol Technol 2012; 63: 116-122

51 Zhang X, Shen L, Li F, Meng D, Sheng J. Arginase induction by heat treatment contributes to amelioration of chilling injury and activation of antioxidant enzymes in tomato fruit. Postharvest Biol Technol 2013; 79: 1-8.

52 Lurie A, Klein JD. Acquisition of low-temperature tolerance in tomatoes by exposure to high temperature stress. J Am Soc Hort Sci 1991; 116: 1007-1012.

53 Saltveit MES. Influence of heat shocks on the kinetics of chilling-induced ion leakage from tomato pericarp discs. Postharvest Biol Technol 2005; 36: 87-92

54 Sevillano L, Sanchez-Ballesta MT, Romojaro F, Flores FB. Physiological, hormonal and molecular mechanisms regulating chilling injury in horticultural species. Postharvest technologies applied to reduce its impact. J Sci Food Agric 2009; 89: 555-573.

cc) (i) $\Theta$ This work is licensed under a Creative Commons Attribution NonCommercial-NoDerivs 3.0 Unported License. The images or other third party material in this article are included in the article's Creative Commons license, unless indicated otherwise in the credit line; if the material is not included under the Creative Commons license, users will need to obtain permission from the license holder to reproduce the material. To view a copy of this license, visit http:// creativecommons.org/licenses/by-nc-nd/3.0/ 